\title{
Effectiveness of Bicycle Safety Helmets in Preventing Facial Injuries in Road Accidents
}

\author{
Rebecca Stier, ${ }^{1, *}$ Dietmar Otte, ${ }^{2}$ Christian Müller, ${ }^{3}$ Maximilian Petri, ${ }^{3}$ Ralph Gaulke, ${ }^{3}$ Christian Krettek, ${ }^{3}$ \\ and Stephan Brand ${ }^{3}$ \\ ${ }^{1}$ Department of Cranio Maxillofacial Surgery, Hannover Medical School, Hannover, Germany \\ ${ }^{2}$ Department for Accident Research, Hannover Medical School, Hannover, Germany \\ ${ }^{3}$ Trauma Department, Hannover Medical School, Hannover, Germany \\ "Corresponding author: Rebecca Stier, Department of Cranio Maxillofacial Surgery, Hannover Medical School (MHH), Carl-Neuberg-Strasse 1, D-30625 Hannover, Germany. Tel: \\ +49-5115324748, Fax: +49-5115324740, E-mail: stier.rebecca@mh-hannover.de
}

Received 2015 May 16; Revised 2016 March 16; Accepted 2016 April 13.

\begin{abstract}
Background: The effectiveness of bicycle safety helmets in preventing head injuries is well- documented. Recent studies differ regarding the effectiveness of bicycle helmets in preventing facial injuries, especially those of the mid-face and the mandible.

Objectives: The present study was conducted to determine the protective effect of a bicycle helmet in preventing mid-face and mandibular fractures.

Patients and Methods: Data from an accident research unit were analyzed to collect technical collision details (relative collision speed, type of collision, collision partner, and use of a helmet) and clinical data (type of fracture).

Results: Between 1999 and 2011, 5,350 bicycle crashes were included in the study. Of these, 175 (3.3\%) had fractures of the mid-face or mandible. In total, 228 mid-face or mandibular fractures were identified. A significant correlation was found between age and relative collision speed, and the incidence of a fracture. While no significant correlation was found between the use of a helmet and the incidence of mid-facial fractures, the use of a helmet was correlated with a significantly increased incidence of mandibular fractures.

Conclusions: Higher age of cyclists and increasing speed of the accident opponent significantly increase the likelihood of sustaining facial fractures. The use of bicycle helmets does not significantly reduce the incidence of mid-facial fractures, while being correlated with an even increased incidence of mandibular fractures.
\end{abstract}

Keywords: Bicyclist, Bicycle Helmet, Facial Injury, Mid-face Fracture, Mandibular Fracture

\section{Background}

As many as 2.4 million reported road accidents occurred in Germany in 2012, involving 387,978 accident victims (Federal Statistical Bureau, Wiesbaden, Germany). Cyclists accounted for $21 \%$ of accident victims (81,162); $19.2 \%$ were injured $(74,370)$ while $0.1 \%$ (406) died (Federal Statistical Bureau, Wiesbaden). In 2012, 53 million residents of Germany possessed 71 million bicycles; the numbers are rising (de.statistica.com). The increasing use of bicycles as a mode of transportation may be attributed to rising fuel prices on the one hand, and the development of mass sports like mountain biking or racing cycling on the other (1). Compared to other traffic participants such as drivers of cars or motorcycles, the cyclist is least protected. Even a minor collision or fall can cause serious injuries as cyclists fall unprotected on the collision partner or the road, quite often headlong $(2,3)$. The cyclist's sole protection is the bicycle helmet. In most cases, it is a simple soft-shell helmet. Because standard bicycle helmets are primary not designed for preventing facial injury, they have no chin guard or face shield. So, we expect no protection to the face. In contrast to Australia, New Zealand or Finland, cyclists are not required to wear helmets by law in Germany. Nevertheless, the number of cyclists who use a helmet is increasing (Federal Statistical Bureau, Wiesbaden; GIDAS) (Figure 1). Several studies have shown that head injuries are more common and more severe when the cyclist does not wear a helmet (4-10). With regard to head injuries, the majority of studies conducted until today have focused on intracranial injuries and the severity of injury. The influence of a bicycle helmet on craniofacial fractures has been poorly analyzed and is, in part, controversially discussed (11-13). These injuries are not life-threatening, but they are often associated with severe morbidity, loss of function, disfigurement, and 
significant financial cost (14).

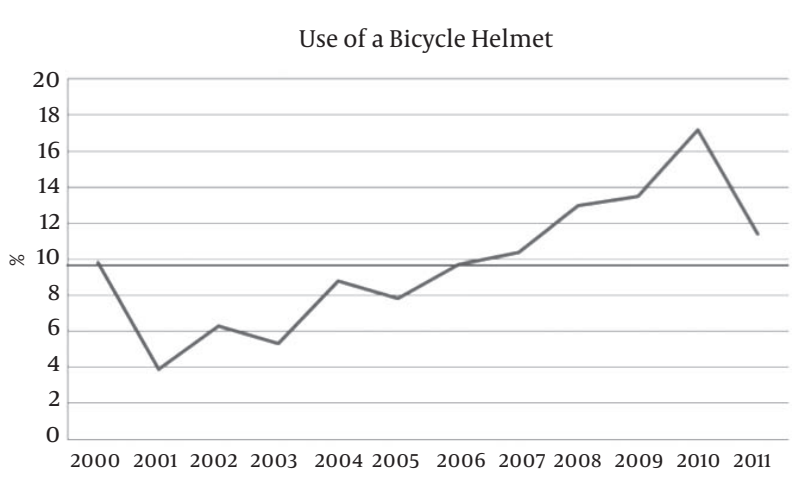

Figure 1. Rates of Frequent Bicycle Helmet Users from 2000 to 2011, Mean 9.8\% (GIDAS)

\section{Objectives}

The aim of the present study was to analyze the effectiveness of bicycle helmets regarding prevention of facial fractures.

\section{Patients and Methods}

The evaluation was based on the data of the German In-Depth accident study (GIDAS). The German In-Depth accident study is a collaborative project of the federal office of road engineering (Bundesanstalt fur Strassenwesen; BaSt, Germany) and the research association of automobile technology (Forschungsvereinigung Automobiltechnik e.V.; FAT, Germany). A random selection method is used at the universities of Hannover and Dresden to register road accidents involving personal injury and evaluating these accidents medically and technically. According to this method, about 2,000 road accidents involving personal injuries are being reported every year in Greater Hannover and Dresden since the 1st of July 1999. A research team consisting of technicians and medical specialists go to the accident site and collect information about traces of the accident, vehicle deformation, injuries, and the cause of the accident. Based on 500 to 3000 data registered per accident, the accident can be reconstructed in detail by the use of a 3D laser technique $(15,16)$. After the accident, the team went to the hospital where the patient was undergoing treatment and recorded the clinical diagnosis. All data were compared to the official accident profiles for the catchment area and analyzed. Thus, GIDAS data were representative of the actual conditions in the surveyed areas (17).
In this study 24,892 accidents were registered from 1999 to 2011, of which 22,347 could be fully reconstructed. The excluded data were: Not completely reconstructed accidents, all traffic participants except bicyclists, fatally injured people. Also, cases with unknown facial injuries or unknown fact of wearing a helmet were excluded. All together we could analyze data from 5,350 cyclists. We evaluated the following data: collision opponents (Table 1), type of collision (Table 1), collision speed (relative speed of the collision partner in $\mathrm{km} / \mathrm{h}$ ), age, gender, the use of a protective helmet, and the presence of a facial fracture (orbital bone, zygomatic bone, nasal bone, maxilla, and mandible). Fractures of the nasal bone, the orbital bone, the zygomatic bone, and the maxilla were grouped together as fractures of the mid-face.

The bicycle is not only use as a cheap mode of transport. The community who use a bicycle for sport activities is increasing. Thus, every year redesigned and faster bicycles were produced by industry. So, there is a large offer on different bicycle types, e.g. city bikes, mountain bikes, road racing bikes, cyclo-cross bikes, BMX bikes, trick riding bikes and E-bikes. The normal road cyclist is generally not mandated to wear specific clothing. A standard bicycle helmet is the sole protection and is developed to protect the head in case of fall or collision. They are not designed to protect the face. So, they have no chin guard or face shield. Bicycle helmets were different in two types, depending in manufacturing method: In-mold-method and selective-sticking-method. The standard bicycle helmet is a soft-shell helmet and is produced in the selective-stickingmethod. In this process the two components (inner plastic foam and outer plastic) were sticked at selective points. So, the acting energy cannot distribute and leads much higher energy in several points. A better protection will be accepted by using the in-mold-method. This technique guaranteed an all-over solid compound from the inner plastic foam and the outer plastic. In case of fall the energy will be a consisted distribution of energy. Hard-shell helmet, micro-shell helmet and some skater helmet are produced in this way (18). Some of those helmets have also an additional chin guard or face shield. Therefore, these kinds of helmets are used for mountain biking, speed biking and road racing biking.

Our data from the GIDAS had no details about the helmet. So, we did not know if the bicyclist wore a soft-shell helmet or hard-shell helmet. Because the data are from road accidents, we believe that most of the helmets were simple soft shell helmets.

This was a multicentrically and retrospectively evaluated comparative study. Data from the included groups were compared to the entire cohort of cyclists.

The data were evaluated retrospectively. SPSS Statistics 
Table 1. Demographic and Accident Data ${ }^{a}$

\begin{tabular}{|c|c|c|c|}
\hline & Total $(n=5350)$ & No Fracture $(n=5175)$ & Fracture $(n=175)$ \\
\hline \multicolumn{4}{|l|}{ Age, $y$} \\
\hline Child, preschool age & $28(0.5)$ & $27(0.5)$ & $1(0.6)$ \\
\hline Child, 6 - 12 years & $363(6.8)$ & $361(7.0)$ & $2(1.1)$ \\
\hline Adolescent, $<17$ years & $483(9.0)$ & $466(9.0)$ & $17(9.7)$ \\
\hline 18 to 64 years & $3684(68.9)$ & $3566(68.9)$ & $118(67.4)$ \\
\hline$>65$ years & $786(14.7)$ & $749(14.5)$ & $37(21.1)$ \\
\hline \multicolumn{4}{|l|}{ Gender } \\
\hline Male & $3151(58.9)$ & $3039(58.7)$ & $112(63.0)$ \\
\hline Female & $2185(40.8)$ & $2122(41.0)$ & $63(36.0)$ \\
\hline \multicolumn{4}{|l|}{ User of a helmet } \\
\hline Yes & $537(10.1)$ & $523(10.1)$ & $14(8.0)$ \\
\hline No & $4813(89.9)$ & $4652(89.9)$ & $161(92.0)$ \\
\hline \multicolumn{4}{|l|}{ Collision partner } \\
\hline Car & $3460(64.7)$ & $3393(65.6)$ & $67(38.3)$ \\
\hline Utility vehicle & $327(6.1)$ & $357(6.9)$ & $15(8.6)$ \\
\hline Motorized two-wheeler & $60(1.1)$ & $59(1.1)$ & $1(0.6)$ \\
\hline Bicycle & $430(8.0)$ & $405(7.8)$ & $25(14.3)$ \\
\hline Pedestrian $^{\mathrm{b}}$ & $117(2.2)$ & $114(2.2)$ & $3(1.7)$ \\
\hline Object & $770(14.4)$ & $714(13.8)$ & $56(32.0)$ \\
\hline Several & $180(3.4)$ & $173(3.3)$ & $7(4.0)$ \\
\hline \multicolumn{4}{|l|}{ Type of collision } \\
\hline (1) Collision with two-wheeler, pedestrian, object, or a fall ${ }^{\mathrm{b}}$ & $1429(26.7)$ & $1427(27.6)$ & $32(18.3)$ \\
\hline (2) The opponent collides frontally with the bicycle & $668(12.5)$ & $644(12.4)$ & $24(13.7)$ \\
\hline (3) The front of the bicycle hits the opponent's side at right angles & $382(7.1)$ & $377(7.3)$ & $5(2.9)$ \\
\hline (4) The front of the bicycle hits the opponent's side obliquely & $840(15.7)$ & $827(16.0)$ & $13(7.4)$ \\
\hline (5) The front of a two-wheeler hits the back of the opponent & $162(3.0)$ & $159(3.1)$ & $3(1.7)$ \\
\hline (6) The front of the opponent hits the back of the opponent & $383(7.2)$ & $375(7.2)$ & $8(4.6)$ \\
\hline (7) The opponent hits the bicycle from the side and collides with it frontally & $1455(27.2)$ & $1367(26.4)$ & $88(50.3)$ \\
\hline Mean age (years) & $39.3($ SD 20.1) & $39.1($ SD 20.1) & $45.3(\mathrm{SD} 19.9)$ \\
\hline Mean speed $(\mathbf{k m} / \mathbf{h})$ & $16.9(\mathrm{SD} 13.2)$ & $16.6(\mathrm{SD} 12.9)$ & $23.2(\mathrm{SD} 17.8)$ \\
\hline
\end{tabular}

${ }^{\mathrm{a}}$ Values are expressed as No. (\%) unless otherwise indicated.

${ }^{\mathrm{b}}$ reference category (for multinominal variables).

(SPSS for Windows, Version 21.0, SPSS Inc, Chicago, USA) was used for statistical analysis. To get an overview of the data, a descriptive analysis was performed (Tables 1 and 2). As related to our issue, we used the binary logistic regression model to analyze the variable "wearing a helmet" to the occurrence of a fracture (Table 3). In the same analysis, we looked for other risk factors for sustaining a facial fracture (Table 3). A binary logistic regression model was performed to analyze the association between the fracture location, wearing a helmet, the relative speed of the opponent and the age (Table 4). The level of significance was set to $\mathrm{P} \leq 0.05$.

\section{Results}

Of 5,350 bicycle accidents, 3.3\% (175) had a fracture of the mid-face and/or mandible. Overall 228 fractures were identified (Table 2). Most frequent fracture was the nasal 
Table 2. Rates of Different Fracture Types Depending on Wearing a Helmet

\begin{tabular}{|c|c|c|c|}
\hline Location of fracture & Helmet & No Helmet & Sum \\
\hline Nasal bone & 8 & 78 & 86 \\
\hline Orbital bone & 2 & 48 & 50 \\
\hline Zygomatic bone & 2 & 37 & 39 \\
\hline Maxilla & 2 & 18 & 20 \\
\hline Mandible & 5 & 13 & 18 \\
\hline Others & 2 & 13 & 15 \\
\hline Sum & 21 & 207 & 228 \\
\hline
\end{tabular}

Table 3. Binary Logistic Regression Analysis: Association Between the Relative Speed of the Opponent, Age and Gender of the Accident Victim, Using a Helmet, the Collision Partner and the Type of Collision (Independent Variables) and the Occurrence of a Fracture (Dependent Variable)

\begin{tabular}{|c|c|c|c|c|c|}
\hline \multirow[t]{2}{*}{ Risk Factors } & \multirow[t]{2}{*}{$\mathbf{B}(\mathbf{S E})$} & \multirow[t]{2}{*}{ Sign. } & \multirow[t]{2}{*}{ Odds Ratio (OR) } & \multicolumn{2}{|c|}{ 95\% Confidence (CI) Interval for OR } \\
\hline & & & & Lower value & Upper value \\
\hline Helmet (yes/no) & $-0.184(0.329)$ & 0.577 & 0.832 & 0.437 & 1.586 \\
\hline Relative Speed (km/h) & $0.042(0.006)$ & $<0.001$ & 1.043 & 1.031 & 1.055 \\
\hline Age, $y$ & $0.015(0.004)$ & 0.001 & 1.015 & 1.006 & 1.023 \\
\hline Gender (male/ female) & $-0.145(0.177)$ & 0.414 & 0.865 & 0.611 & 1.225 \\
\hline \multicolumn{6}{|l|}{ Collision partner ${ }^{a}$} \\
\hline Car & $-0.296(0.598)$ & 0.622 & 0.744 & 0.231 & 2.403 \\
\hline Utility vehicle & $0.612(0.642)$ & 0.340 & 1.845 & 0.524 & 6.491 \\
\hline Motorized two-wheeler & $-0.044(1.166)$ & 0.706 & 0.644 & 0.066 & 6.328 \\
\hline Bicycle & $0.852(0.620)$ & 0.169 & 2.346 & 0.696 & 7.909 \\
\hline Object & $1.09(0.601)$ & 0.069 & 2.980 & 0.917 & 9.682 \\
\hline Several & $-0.627(0.701)$ & 0.387 & 0.534 & 0.392 & 6.105 \\
\hline \multicolumn{6}{|l|}{ Type of collision ${ }^{b}$} \\
\hline Typ 2 & $0.487(0.272)$ & 0.075 & 1.628 & 0.951 & 2.787 \\
\hline Typ 3 & $-0.546(0.484)$ & 0.259 & 0.579 & 0.224 & 1.495 \\
\hline Typ 4 & $-0.377(0.332)$ & 0.256 & 0.686 & 0.358 & 1.314 \\
\hline Typ 5 & $-0.195(0.610)$ & 0.749 & 0.823 & 0.249 & 2.719 \\
\hline Typ 6 & $-0.071(0.400)$ & 0.857 & 0.931 & 0.425 & 2.036 \\
\hline Typ 7 & $1.034(0.210)$ & $<0.001$ & 2.812 & 1.864 & 4.244 \\
\hline
\end{tabular}

${ }^{a}$ reference category: pedestrians.

${ }^{\mathrm{b}}$ reference category: collision with two-wheeler, pedestrian, object, or a fall (Type 1).

bone (38.1\%), followed by orbital bone (21.7\%), zygomatic bone $(17.3 \%)$, maxilla $(8.4 \%)$, mandible $(8.0 \%)$ and others (no specific description of fracture types; $6.5 \%$ ) (Figure 2). The principal characteristics of all accident victims are shown in Table 1. We had missing data as follows: unknown age $6(0.1 \%)$, unknown gender $14(0.3 \%)$, unknown collision partner $6(0.1 \%)$ and unknown collision type 31 (0.6\%), unknown speed $911(17 \%)$. The age of the victims ranged be- tween 2 and 89 years with a mean age of 39 years unrelated to gender (SD 20,1). The mean age of all patients with a fracture was 45 years (SD 20.1). A significant association was found between the patient's age and the incidence of a fracture with an increase of fractures in the elderly (Table 3). We registered a male to female ratio of 1:1.4 for all accident victims, and a ratio of 1:1.7 for all persons who sustained a fracture. No statistical significance was found between the 
Table 4. Binary Logistic Regression Analysis: Association Between Fracture Location (Dependent Variable) and Wearing a Helmet, Relative Speed of the Opponent and Age of the Victim (Independent Variable)

\begin{tabular}{|c|c|c|c|c|c|}
\hline \multirow[t]{2}{*}{ Fracture location } & \multirow[t]{2}{*}{$\mathbf{B}(\mathbf{S E})$} & \multirow[t]{2}{*}{ Sign } & \multirow[t]{2}{*}{ Odds Ratio (OR) } & \multicolumn{2}{|c|}{ 95\% Confidence (CI) Interval for OR } \\
\hline & & & & Lower Value & Upper Value \\
\hline \multicolumn{6}{|l|}{ Nasal bone } \\
\hline Helmet (yes/no) & $0.002(0.434)$ & 0.997 & 1.002 & 0.428 & 2.345 \\
\hline Relative speed (km/h) & $0.018(0.008)$ & 0.017 & 1.018 & 1.003 & 1.034 \\
\hline \multicolumn{6}{|l|}{ Maxilla } \\
\hline Helmet (yes/no) & $-0.194(1.045)$ & 0.852 & 0.823 & 0.106 & 6.385 \\
\hline Relative speed $(\mathbf{k m} / \mathbf{h})$ & $0.019(0.016)$ & 0.253 & 1.019 & 0.987 & 1.051 \\
\hline Age, $y$ & $0.02(0.013)$ & 0.127 & 1.020 & 0.994 & 1.046 \\
\hline \multicolumn{6}{|l|}{ Mandible } \\
\hline Relative speed $(\mathbf{k m} / \mathbf{h})$ & $0.038(0.014)$ & 0.007 & 1.039 & 1.011 & 1.067 \\
\hline Age, $y$ & $0.008(0.014)$ & 0.595 & 0.992 & 0.965 & 1.021 \\
\hline \multicolumn{6}{|l|}{ Zygomatic bone } \\
\hline Helmet (yes/no) & $-0.266(0.738)$ & 0.717 & 0.766 & 0.180 & 3.251 \\
\hline Relative speed (km/h) & $0.028(0.010)$ & 0.004 & 1.028 & 1.008 & 1.047 \\
\hline Age, $y$ & $0.028(0.009)$ & 0.001 & 1.028 & 1.011 & 1.045 \\
\hline \multicolumn{6}{|l|}{ Orbital bone } \\
\hline Helmet (yes/no) & $-0.557(0.735)$ & 0.448 & 0.573 & 0.136 & 2.418 \\
\hline Relative speed (km/h) & $0.046(0.007)$ & $<0.001$ & 1.047 & 1.032 & 1.062 \\
\hline Age, $y$ & $0.028(0.007)$ & $<0.001$ & 1.028 & 1.013 & 1.043 \\
\hline
\end{tabular}

incidence of a fracture and gender. A protective helmet was worn by $10.1 \%$ of all cyclists, and only by $8 \%$ of those with a fracture. Also, $13.1 \%$ of male accident victims and $5.6 \%$ of female accident victims wore a helmet. The use of helmets was significantly dependent on gender and age; decreasing with advancing age and female gender. The distribution of collision partners and types is shown in Table 1 . The most frequent collision partners were cars, objects (also falls) and other bicyclists in the group with a fracture. The mean speed of the collision partner at the time of collision was $16.9 \mathrm{~km} / \mathrm{h}$ (SD 13.1). Considering all patients with a fracture, the mean speed was $23.2 \mathrm{~km} / \mathrm{h}$ (SD 19.4). A significant association was noted between one type of collision (Type 7: the opponent hits the bicycle from the side and collides with it frontally), the opponents speed, and the probability of a fracture of the mid-face, nose, or mandible (Table 3). In general, we found no correlation between the collision partner and the incidence of a fracture (Table 3). The distribution of fractures is shown in Figure 2. We registered no significant association between the use of a helmet and the likelihood of experiencing a mid-facial fracture (Table
3). Investigation of individual fractures showed that the use of a helmet increased the incidence of mandibular fractures (OR 3.981, CI 1.204-13.168) (Table 4). Contrary to this, we found a tendency towards protective effects of the helmet to the maxilla (OR 0.823, CI 0.106 - 6.385), the orbital bone (OR 0.573, CI 0.136 - 2.418), zygomatic bone (OR 0.766, CI 0.180 - 3.251) and nasal bone (OR 1.002, CI 0.428 - 2.345) (Table 4). The same analysis showed that the speed had no effect on fractures of the maxilla and that the age has no effect on maxilla and mandible fractures (Table 4).

\section{Discussion}

The most important finding of this study was that the use of bicycle helmets does not reduce the incidence of mid-facial fractures, while being correlated with an even increased incidence of mandibular fractures.

We performed a detailed technical and medical investigation of 5,350 cyclists who were involved in road accidents; 3.3\% (175) of them suffered from a facial fracture. Similar rates (between 3.3\% and 9.9\%) have been reported 


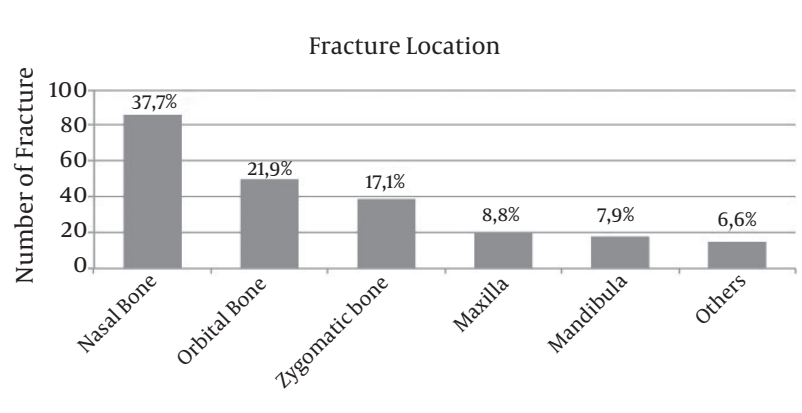

Figure 2. Location of Fracture (\%) of All 228 Facial Fractures Based on 175 Patients

in the published literature (19-21). The majority of the accident victims were men between the first and third decade of their lives, which is also in conformity with published data $(19,22)$. Among patients with fractures, the majority were men aged 30 to 49 years. Similar data have been reported by Lindqvist et al. (21). Our data revealed a significant correlation between the patient's age and the likelihood of suffering from a facial fracture. Reaction speed, balance, vision, hearing abilities and bone density deteriorate with advancing age (23). All of these factors might explain the correlation.

Despite the increasing use of bicycle helmets in the last decade, the rate of helmet wearers $(10.1 \%)$ was unexpectedly low in the present study. We found no explanation for the sudden drop of these rates in 2011 (Figure 1). Among patients with a facial fracture, only $8 \%$ wore a helmet. However, recent data from the GIDAS showed a rising number of helmet usage (15.4\%) in 2013. A much higher rate of helmet wearers was found in the literature. Amoros et al. 2012 (France) reported that about $26 \%$ of bicyclists had worn a helmet (24). Rivara et al. 1997 (Seattle, USA) reported about 52.5\% (25) and de Rome et al. 2014 (Australia) about 89\% (26). In most cases the research was from states or districts with a helmet wearing legislation. In Australia the helmet use increased in Melbourne from 36\% (pre-law) to 83\% (post- law) and in the state of Victoria from 31.5\% to 75\% (9). In contrast, other studies reported about $2.1 \%$ to $6 \%$ bicyclist wearing a helmet in $\operatorname{Brazil}(27,28)$. In our study women wore rarely a helmet than men $(\mathrm{w}: \mathrm{m}=1: 2.5)$. Same results were found in the literature $(24,29)$. A reason could be that women have more concerns about fashion and hairstyle. The acceptance of a helmet was highest (65.8\%) among children below 12 years of age, and started to fall with advancing age. There are different reasons for wearing a helmet or not wearing a helmet in literature. The major factors leading to teenagers not wanting to wear a helmet were appearance and comfort (30). Ritter et al. 2011 found that household demographics, residential location, and riding patterns are significant correlates of helmet use (29). Also, the urban residency, household income, and the presence of children in the household have a positive effect on the probability of helmet use (29).

Bicycle accidents are caused by various factors: the cyclist and/or the opponent riding/driving too fast, inattentiveness, poor driving conditions, limited visibility, or mechanical failure (22). The majority of bicycle accidents occur in road traffic: cyclists collide with cars, other cyclists, or pedestrians $(16,31,32)$. Our investigation showed that fractures usually occur during collisions with a car, an object (also a fall), or another cyclist. The authors of other studies $(11,12,19,20,32)$ registered many more falls than we did. However, these studies included falls from bicycles due to all causes, whereas the (GIDAS) only took falls due to road accidents into account, the majority of which involved other road users as well. We found an association between one type of collision (Type 7: the opponent hits the bicycle from the side and collides with it frontally) and the occurrence of a fracture in our statistical analysis (Table 3 ).

In our investigation, the speed of the opponent in the accident had a major impact on the likelihood of experiencing a facial fracture. The mean speed of the collision partner at time of collision was $23.2 \mathrm{~km} / \mathrm{h}$ in all patients with a fracture. The force exerted on bone increases with speed, and thus the likelihood of a fracture. An experimental study by Syed et al. used video analysis techniques to determine the velocity, impact force, angle of impact, and impulse to fracture involved in a video-recorded bicycle accident resulting in facial fractures. The results showed that an impact velocity of $6.25 \mathrm{~m} / \mathrm{s}(22.5 \mathrm{~km} / \mathrm{h})$ and a force of 1910.4 N with the head angled at a 14-degree extension and a 6.3-degree axial rotation to the left can result in a bilateral Le Fort 3 and 2 fractures (33). Also, Rivara et al. 1997 described that the speed at the time of crash is a risk factor for serious head, face and neck injuries (25).

Among all fractures, mid-face fractures occurred very often (85.5\%). We were unable to perform an exact classification of the fractures in terms of a Le Fort or NOE (nasoorbitoethmoidal) fracture because the GIDAS study does not provide data about the type and location of fractures. We do not know whether a fracture of the nasal bone, for instance, was an isolated injury or part of a combined Le Fort fracture.

Mandibular fractures occurred in $8 \%$ of the cases. Of interest, we found that the probability of a mandibular fracture is even increasing with helmet protection. On the other hand, we found a tendency towards a protective effect of wearing a helmet to the maxilla, orbital bone, zygomatic bone and nose, however without reaching statistical significance. From the biomechanical point of view, the force of a fall is curbed by the protective element, which 
is the helmet. At the time of crash the helmet hides first. Afterwards the unprotected mandible crashed because of the hyperflexion in the cervical spine. In cases with no helmet, the forces are spread all over the facial bones. While the mandible is a stable single bone, the mid-face consists of several individual bones, some of them just $2 \mathrm{~mm}$ thick, and large pneumatized cavities. Therefore, the probability of a mid-facial fracture is much higher. The same mechanism was described by Hwang et al. in a review from 2015 (10). In case-control studies performed by Thompson et al. $(9,12,13,34)$, the helmet was found to exert also a protective effect on the upper and mid-face in $65 \%$ of cases. The study performed in 1990 included soft tissue injuries and fractures, while the second study (34) consisted exclusively of soft tissue injuries. In 1993, McDermott et al. described a reduction of facial injuries by $28 \%$ by the use of a bicycle helmet (35). However, the authors did not mention which facial injuries they recorded. The same author reported two years later that face injuries were less frequent in approved helmet wearers (24.9\%) (36). In both studies authors do not mention which facial injuries they recorded. In 2000 Thompson et al. performed a meta-analysis for the Conchrane collaboration. The review contains five studies of crashed cyclists, including their own studies from 1989 and 1996 and also the study by McDermott, 1993. The main outcome was that helmets decrease the risk of facial injury to the upper and mid face by $65 \%$ (9). A present review from 2015 performed by Hwang et al. showed that a bicycle helmet covers the upper and middle face from serious facial injury but cannot cover the lower face (10).

A meta-analysis based on 16 estimates of the effect on head, face and neck injuries of wearing a bicycle helmet concluded that the risk of facial injury reduced by $27 \%$ (37). A present French study indicates that helmet wearing lowers the risk of facial injuries (24). This study included any facial injury with no separation of lacerations or fractures.

Just a few studies found no effect in preventing facial injuries. In a case-control study in Finland (11), the authors registered the protective effect of a hard shell bicycle helmet on head injuries, but not facial injuries.

Several studies reported that mandibular fractures are common in bicycle injuries $(21,38)$ while other studies also reported more fractures in the mid-face $(19,20)$. However, none of these studies reported if the cyclists wore a helmet or not.

The strongest limitation of our study was the small number of persons with helmet protection. So, the statistical analysis was vulnerable for coincidence and bias. We also had 911 cases (17\%) with missing data of the speed and did not know what kind of helmet was worn. Second, we were unaware of the exact location of the fractures. Therefore, it is difficult to separate the possible effect of the hel- met on different fracture types. Furthermore, this fact hindered comparison of our data with those of other studies.

As a perspective, we intend to repeat the investigation in five years' time to reproduce these data in a larger population. Furthermore, we plan to use dummies for a biomechanical investigation of the force exerted on the mandible and the mid-face to determine a protective effect of modified bicycle helmets on mid-facial and mandibular fractures.

\subsection{Conclusion}

Higher age of cyclists and increasing speed of the accident opponent significantly increase the likelihood of sustaining facial fractures. The use of bicycle helmets does not significantly reduce the incidence of mid-facial fractures, while being correlated with an even increased incidence of mandibular fractures.

\section{Footnote}

Financial Disclosure: None of the authors have any financial interests related to the material in the manuscript.

\section{References}

1. Strohm PC, Sudkamp NP, Zwingmann J, El Saman A, Kostler W. [Polytrauma in cyclists. Incidence, etiology, and injury patterns]. Unfallchirurg. 2005;108(12):1022-4. doi: 10.1007/s00113-005-0975-3. [PubMed: 16032368] 1026-8.

2. Bostrom L, Nilsson B. A review of serious injuries and deaths from bicycle accidents in Sweden from 1987 to 1994. J Trauma. 2001;50(5):900-7. [PubMed: 11371849].

3. Guzel A, Ersoy B, Dogrusoy Y, Kucukugurluoglu Y, Altinel T, Karasalihoglu S. [The evaluation of bicycle accidents that were admitted to a pediatric emergency department]. Ulus Travma Acil Cerrahi Derg. 2006;12(4):299-304. [PubMed:17029120].

4. Fernandez Sanmartin M, Cabanas Rodriguez P, Granero Asencio M, Saavedra Chaves E, Martinez Perez L, Berdullas Rodriguez MI, et al. [Change in attitude to bicycle helmets after serious accidents]. An Pediatr(Barc). 2004;60(2):189-90. [PubMed:14757030].

5. Pathirana AA, Senaratne JW, Sheriffdeen AH. A study of 100 bicycle accidents. Ceylon Med J. 1997;42(4):205-6. [PubMed: 9476413].

6. Zentner J, Franken H, Lobbecke G. Head injuries from bicycle accidents. Clin Neurol Neurosurg. 1996;98(4):281-5. [PubMed: 8930417].

7. Brand S, Otte D, Petri M, Muller C, Stubig T, Krettek C, et al. Bicyclistbicyclist crashes-a medical and technical crash analysis. Traffic Inj Prev. 2013;14(1):56-60. doi: 10.1080/15389588.2012.688152. [PubMed: 23259519].

8. Gonzalez Pacheco N, Maranon Pardillo R, Storch de Gracia Calvo P, Campos Calleja C, Mojica Munoz E, Rodriguez Saez MJ, et al. [Bicycle accidents treated in emergency departments. A multicentre study]. An Pediatr (Barc). 2014;80(4):242-8. doi: 10.1016/j.anpedi.2013.05.031. [PubMed: 23849728].

9. Thompson DC, Rivara FP, Thompson R. Helmets for preventing head and facial injuries in bicyclists. Cochrane Database Syst Rev. 2000(2):001855. doi: 10.1002/14651858.CD001855. [PubMed: 10796827]. 
10. Hwang K, Jeon YM, Ko YS, Kim YS. Relationship between Locations of Facial Injury and the Use of Bicycle Helmets: A Systematic Review. Arch Plast Surg. 2015;42(4):407-10. doi: 10.5999/aps.2015.42.4.407. [PubMed: 26217559].

11. Hansen KS, Engesaeter LB, Viste A. Protective effect of different types of bicycle helmets. Traffic Inj Prev. 2003;4(4):285-90. doi: 10.1080/714040486. [PubMed: 14630577].

12. Thompson DC, Thompson RS, Rivara FP, Wolf ME. A case-control study of the effectiveness of bicycle safety helmets in preventing facial injury. Am J Public Health. 1990;80(12):1471-4. [PubMed: 2240332].

13. Thompson RS, Rivara FP, Thompson DC. A case-control study of the effectiveness of bicycle safety helmets. N Engl J Med. 1989;320(21):13617. doi: 10.1056/NEJM198905253202101. [PubMed: 2716781].

14. Brasileiro BF, Passeri LA. Epidemiological analysis of maxillofacial fractures in Brazil: a 5-year prospective study. Oral Surg Oral Med Oral Pathol Oral Radiol Endod. 2006;102(1):28-34. doi: 10.1016/j.tripleo.2005.07.023. [PubMed:16831669].

15. Richter M, Otte D, Gansslen A, Bartram H, Pohlemann T. Injuries of the pelvic ring in road traffic accidents: a medical and technical analysis. Injury. 2001;32(2):123-8. [PubMed: 11223043].

16. Richter M, Otte D, Haasper C, Knobloch K, Probst C, Westhoff $\mathrm{J}$, et al. The current injury situation of bicyclists-a medical and technical crash analysis. J Trauma. 2007;62(5):1118-22. doi: 10.1097/01.ta.0000221060.78894.cb. [PubMed:17495710].

17. Otte D, Jansch M, Haasper C. Injury protection and accident causation parameters for vulnerable road users based on German InDepth Accident Study GIDAS. Accid Anal Prev. 2012;44(1):149-53. doi: 10.1016/j.aap.2010.12.006. [PubMed: 22062349].

18. State ministry for environment and consumer protection of bavaria Available from: www.vis.bayern.de.

19. Lee $\mathrm{KH}$, Chou HJ. Facial fractures in road cyclists. Aust Dent J. 2008;53(3):246-9. doi: 10.1111/j.1834-7819.2008.00056.x. [PubMed: 18782369].

20. Gassner RJ, Hackl W, Tuli T, Fink C, Waldhart E. Differential profile of facial injuries among mountainbikers compared with bicyclists. $J$ Trauma. 1999;47(1):50-4. [PubMed:10421186].

21. Lindqvist C, Sorsa S, Hyrkas T, Santavirta S. Maxillofacial fractures sustained in bicycle accidents. Int J Oral Maxillofac Surg. 1986;15(1):12-8. [PubMed: 3083000].

22. Thompson MJ, Rivara FP. Bicycle-related injuries. Am Fam Physician. 2001;63(10):2007-14. [PubMed: 11388717].

23. Brand S, Otte D, Mueller CW, Petri M, Haas P, Stuebig T, et al. Injury patterns of seniors in traffic accidents: A technical and medical analysis. World J Orthop. 2012;3(9):151-5. doi: 10.5312/wjo.v3.i9.151. [PubMed: 23173111].

24. Amoros E, Chiron M, Martin JL, Thelot B, Laumon B. Bicycle helmet wearing and the risk of head, face, and neck injury: a French case- control study based on a road trauma registry. Inj Prev. 2012;18(1):2732. doi: 10.1136/ip.2011.031815. [PubMed: 21606469].

25. Rivara FP, Thompson DC, Thompson RS. Epidemiology of bicycle injuries and risk factors for serious injury. Inj Prev. 1997;3(2):110-4. [PubMed: 9213156].

26. de Rome L, Boufous S, Georgeson T, Senserrick T, Ivers R. Cyclists' clothing and reduced risk of injury in crashes. Accid Anal Prev. 2014;73:392-8. doi:10.1016/j.aap.2014.09.022. [PubMed: 25305805].

27. Junior SM, Santos SE, Kluppel LE, Asprino L, Moreira RW, de Moraes M. A comparison of motorcycle and bicycle accidents in oral and maxillofacial trauma. J Oral Maxillofac Surg. 2012;70(3):577-83. doi: 10.1016/j.joms.2011.03.035. [PubMed: 21665346].

28. Santos SE, Soares AJ, de Souza Filho FJ, de Moraes M, Moreira RWF. A 9-year retrospective study of dental trauma in Piracicaba and neighboring regions in the state of Sao Paulo, Brazil.Journal of Oral and Maxillofacial Surgery. 2010;68:1826-32.

29. Ritter N, Vance C. The determinants of bicycle helmet use: evidence from Germany. Accid Anal Prev. 2011;43(1):95-100. doi: 10.1016/j.aap.2010.07.016. [PubMed: 21094302].

30. Finch CF. Teenagers' attitudes towards bicycle helmets three years after the introduction of mandatory wearing. Inj Prev. 1996;2(2):126-30. [PubMed: 9346076].

31. Zwipp H, Barthel P, Bonninger J, Burkle H, Hagemeister C, Hannawald L, et al. [Prevention of bicycle accidents]. Z Orthop Unfall. 2015;153(2):177-86. doi: 10.1055/s-0034-1396260. [PubMed: 25874397].

32. Thompson DC, Thompson RS, Rivara FP. Incidence of bicycle-related injuries in a defined population. Am J Public Health. 1990;80(11):138890. [PubMed: 2240316].

33. Syed SH, Willing R, Jenkyn TR, Yazdani A. Video analysis of the biomechanics of a bicycle accident resulting in significant facial fractures. J Craniofac Surg. 2013;24(6):2023-9. doi: 10.1097/01.scs.0000436699.43090.34. [PubMed: 24220396].

34. Thompson D, Rivara FP, Thompson R. Bicycle helmet use. Inj Prev. 1996;2(4):304. [PubMed: 9346113].

35. McDermott FT, Lane JC, Brazenor GA, Debney EA. The effectiveness of bicyclist helmets: a study of 1710 casualties. J Trauma. 1993;34(6):83444. [PubMed: 8315679].

36. McDermott FT. Bicyclist head injury prevention by helmets and mandatory wearing legislation in Victoria, Australia. Ann R Coll Surg Engl. 1995;77(1):38-44. [PubMed: 7717644].

37. Attewell RG, Glase K, McFadden M. Bicycle helmet efficacy: a metaanalysis. Accid Anal Prev. 2001;33(3):345-52. [PubMed:11235796].

38. Yamamoto K, Matsusue Y, Horita S, Murakami K, Sugiura T, Kirita T. Maxillofacial fractures sustained in bicycle accidents. J Oral Maxillofac Surg. 2011;69(6):155-60. doi: 10.1016/j.joms.2010.12.028. [PubMed: 21496994]. 